\title{
Perancangan dan Implementasi Survei Kepuasan Stakeholder Alumni Berbasis Web
}

\author{
Design And Implementation Of Web-Based Alumni Stakeholder Satisfaction Survey
}

\author{
Wettria Anggraini ${ }^{1}$, Nugroho Agung Prabowo ${ }^{2}$, Endah Ratna Arumi ${ }^{3}$ \\ ${ }^{1,2,3}$ Teknik Informatika, Universitas Muhammadiyah Magelang \\ E-mail: ${ }^{1}$ wettriaanggraini@gmail.com, ${ }^{2}$ naprabowo@ummgl.ac.id, ${ }^{3}$ arumi@ummgl.ac.id
}

\begin{abstract}
Abstrak
Survei kepuasan stakeholder merupakan salah satu cara yang dilakukan institusi dalam mengontrol sebaran alumni yang telah bekerja pada instansi/institusi di wilayah tertentu. Kualitas alumni perguruan tinggi termasuk gambaran yang dapat dijadikan acuan kualitas Sumber Daya Manusia (SDM) dari institusi pendidikan tersebut. Selama ini survei kepuasan pelanggan dilakukan dengan cara menyebarkan angket kuisioner kepada seluruh stakeholder, dan harus mendatangi langsung tempat alumni bekerja. Hasil dari kuisioner yang telah disebarkan, kemudian dikumpulkan kepada pihak kemahasiswaan untuk dilakukan perhitungan agar mendapatkan nilai rata-rata hasil kepuasan stakeholder berdasarkan alumni yang bekerja di instansinya. Dengan semakin berkembangannya teknologi informasi pada internet dan web, memungkinkan untuk dapat dirancang sebuah sistem survei kepuasan stakeholder alumni yang berbasis web, agar memudahkan stakeholder dalam pengisian kuisioner karena dapat diisi dimana dan kapan saja. Penelitian ini menghasilkan sistem survei stakeholder, yang dapat memonitoring kualitas alumni didunia kerja berdasarkan hasil penilaian dari stakeholder tempat alumni bekerja. Dari hasil uji coba acceptance testing yang dilakukan kepada stakeholder maka didapat hasil penilaian $67 \%$ yang artinya responden cukup puas dengan sistem.
\end{abstract}

Kata Kunci: Alumni, Survei Kepuasan Stakeholder, Penyebaran Alumni.

\begin{abstract}
A stakeholder satisfaction survey is one of the ways conducted by institutions in controlling the distribution of alumni who have worked in institutions/institutions in certain regions. The quality of higher education alumni includes an image that can be used as a reference for the quality of Human Resources (HR) from the educational institution. During this time the customer satisfaction survey was carried out by distributing questionnaires to all stakeholders and had to go directly to the place where the alumni worked. The results of the questionnaire that has been distributed, then collected to the students to be calculated in order to get an average value of stakeholder satisfaction results based on alumni who work in their institutions. With the growing development of information technology on the internet and the web, it is possible to design a web-based alumni stakeholder satisfaction survey system, to facilitate stakeholders in filling out the questionnaire because it can be filled anywhere and anytime. This research produces a stakeholder survey system, which can monitor the quality of alumni in the world of work based on the results of an assessment of the stakeholders where the alumni work. From the results of the trials conducted to the teaching staff and the company, it shows the figure of $67 \%$ which means that the respondents are quite satisfied with the system.
\end{abstract}

Keywords: Alumni, Stakeholder Satisfaction Survey, Alumni Distribution.

\section{PENDAHULUAN}

Alumni merupakan unsur yang tak dapat dipisahkan dari perguruan tinggi, karena alumni adalah representatif dari perguruan tinggi. Alumni membawa manfaat tersendiri bagi perguruan tinggi, baik dalam akademik maupun bidang pragmatis, seperti: 1) Pemutakhiran kurikulum berbasis relevansi dengan kebutuhan pasar/dunia kerja; 2) Continuing Education: Universitas 
dapat dikembangkan menjadi media belajar sepanjang hayat bagi alumni; 3) tamu, dosen profesional, seminar, Training dan lain - lain [1]. Salah satu upaya yang dilakukan dalam rangka memperbaiki layanan adalah melakukan survei kepuasan [2]. Survei yang dilakukan oleh Perguruan Tinggi digunakan untuk mendapatkan data, melakukan penyelidikan dan peninjauan terhadap kualitas dari alumni. Perkembangan teknologi yang semakin pesat saat ini sudah memberikan dampak bagi seluruh aspek kehidupan manusia. Dampak yang jelas terlihat adalah bahwa teknologi telah memudahkan segala aktifitas manusia, tidak dipungkiri kini segala hal yang dulunya bersifat manual sekarang telah berganti bersifat otomatis [3].

Pada implementasi sistem kepuasaan pengguna (User Satisfaction) merupakan salah satu ukuran kesuksesan [4]. Pengguna akhir dapat didefinisikan sebagai pengguna final atau akhir atas sesuatu yang dimaksud [5]. Jika pengguna tidak puas dengan suatu sistem informasi, maka sulit untuk mempertimbangkan keberhasilan suatu sistem informasi [6]. Seandainya hasil yang diperoleh melebihi harapan, tentu pengguna akan merasa sangat puas [5]. Aspek yang dibutuhkan dalam pertanyaan pada kuesioner alumni terkait masalah keberadaan alumni setelah lulus, seberapa lama masa tunggu alumni dalam mendapatkan sebuah pekerjaan, jenis pekerjaan, kesesuaian pekerjaan dengan jurusan, kesesuaian skill yang dapat dengan yang digunakan saat sudah bekerja apakah sudah sesuai dengan kebutuhan stakeholder [1].

Universitas Muhammadiyah Magelang khususnya Lembaga Pengembangan Mahasiswa dan Alumni (LPMA), sebagai wadah untuk pengembangan mahasiswa dan alumni sehingga sangat berperan penting terhadap kualitas lulusan. LPMA melalui Divisi Pemberdayaan Alumni belum sepenuhnya mengetahui kualitas alumni didunia kerja, Universitas Muhammadiyah Magelang melalui fakultas mempunyai tugas untuk mengontrol alumni yang telah terjun kedunia kerja. Saat ini pihak fakultas belum melakukan survei kepuasan stakeholder, sehingga pihak fakultas harus merekap hasil dari tracer study yang alumni isikan untuk mendapatkan data seluruh nama stakeholder tempat alumni bekerja, kemudian mencetak bank kusioner lalu menyebar ke stakeholder terkait, menunggu beberapa saat lalu mengambil kembali kuisioner tersebut dengan selanjutnya menghitung hasilnya. Langkah tersebut memerlukan waktu survei yang sangat lama, dan terdapat beberapa stakeholder yang tidak mengembalikan kusioner yang telah dibagikan karena kesibukan dari pihak stakeholder tersebut, sehingga hasil yang didapatkan kurang optimal. Di dalam penentuan pertanyaan dalam kuisioner untuk survei alumni yang digunakan oleh Fakultas Teknik yaitu penilaian kualitas alumni pada borang akreditasi program studi dari BAN-PT. Penilaian kinerja melalui survei perlu dilakukan untuk mendapatkan hasil yang obyektif dan transparan [7].

Penelitian yang dilakukan oleh [1]., Jurnal jurusan Teknik Informatika yang berudul "Sistem Informasi Administrasi Tracer Study Dan Kepuasan Stakeholders Alumni Stt Nurul Jadid Berbasis Web" [1]. Pendekatan yang digunakan dalam penelitian adalah pendekatan terstruktur yang menggunakan beberapa alat bantu dan teknik pengerjaan, seperti flowchart, conteks diagram, dan Data Flow Diagram (DFD). Pertanyaan untuk Kuesioner stakeholder meliputi tentang masalah skill alumni, kesesuaian kurikulum yang diajarkan di kampus dengan pekerjaan, kebutuhan keahlian dalam pekerjaan, etika alumni saat bekerja, kedisiplinan alumni, saran perbaikan kurikulum. Dalam melakukan pengujian dengan menggunakan blackbox dalam pengujiannya dengan menggunakan pendekatan pengujian terhadap seluruh fungsi menu pada sistem.

Penelitian yang dilakukan oleh Bora yang berjudul "Analisa Kepuasan Penggunaan ELearning Cloud Sekolah Tinggi Teknik (STT) Ibnu Sina Batam" [8]. Penelitian ini menggunakan jenis penelitian deskriptif kuantitatif dan kualitatif untuk mengukur kepuasan pengguna elearning cloud di STT Ibnu Sina Batam. Metode pengumpulan data yang digunakan dalam penelitian ini adalah Kuesioner dan Studi Pustaka. Jumlah sampel dalam penelitian ini yaitu 73 responden, teknik pengambilan yang digunakan yaitu teknik Non Probability Sampling jenis Accidental Sampling. Setelah dilakukan pengolahan data menggunakan uji validitas, uji reliabilitas dan analisa kualitatif diperoleh bahwa Responden puas $(\mathrm{P})$ dengan penggunaan Elearning cloud STT Ibnu Sina Batam dengan jawaban responden sebesar 41\%, responden yang menjawab sangat puas (SP) sebesar 32\%, responden yang menjawab cukup puas (CP) sebesar 
$13 \%$, responden yang menjawab kurang puas (KP) sebesar 9\% dan jawaban responden sangat Tidak Puas (STP) sebesar 5\%.

Penelitian yang dilakukan oleh Ardianto yang berjudul "Faktor-Faktor Yang Mempengaruhi Kepuasan Pengguna Akhir Sistem Informasi Sumber Daya Manusia (Studi Kasus Di BPK RI)" [9]. Penelitian ini menggunakan modifikasi sebagian taksonomi yang terdapat dalam model keberhasilan sistem informasi. Selain itu dilakukan modifikasi dengan menambahkan Second Order Confirmatory Factor Analysis (CFA) terhadap variabel User Satisfaction. Pengujian dilakukan dengan metode Structural Equation Modeling (SEM). Hasilnya menunjukkan bahwa kualitas sistem dan kualitas informasi berpengaruh terhadap perceived usefulness; kualitas informasi, kualitas layanan dan perceived usefulness berpengaruh terhadap kepuasan pengguna akhir. Sedangkan kualitas sistem tidak berpengaruh terhadap kepuasan pengguna akhir.

Berdasarkan penelitian yang relevan, maka penelitian ini akan merancang sebuah sistem informasi survei kepuasaan stakeholder sebagai acuan untuk peningkatan kualitas alumni tiap tahun di dunia kerja yang berbasis website. Pengumpulan data dilakukan dengan wawancara dan survei ke stakeholder. Perancangan sistem yang dibuat menggunakan metode penyebaran kuesioner secara online, kuesioner akan diisi melalui web sehingga tidak perlu untuk menyebar dan mengumpulkan kembali kuesioner yang telah diisi oleh stakeholder. Hasil kuesioner akan diolah oleh sistem sehingga perhitungan lebih akurat. Sistem ini akan lebih efisien karena tidak perlu bertatap muka untuk mengisi kuesioner. Kuisoner yang disajikan melalui pelaksanaan survei kepuasan stakeholder dilakukan dengan tujuan antara lain perbaikan proses pembelajaran, informasi lowongan pekerjaan, pengembangan jejaring, penggalangan dana. Pertanyaan survei untuk pengguna lulusan, meliputi integritas, profesionalisme, Bahasa Inggris, komunikasi, TIK, kerjasama tim, pengembangan diri.

Dalam pengujian sistem dibagi menjadi dua yaitu pengujian dengan menggunakan blackbox dan uji validasi serta uji reliabilitas. Pengujian menggunakan blackbox adalah pengujian yang dilakukan untuk mengamati hasil eksekusi melalui data uji dan memeriksa fungsional dari perangkat lunak apakah sesuai dengan fungsinya, sedangkan uji validasi serta uji reliabilitas yang dilakukan adalah dengan metode kuantitatif [8]. Metode kuantitatif dapat diambil hasilnya melalui kuesioner yang diberikan kepada pengguna responden [9]. Penelitian ini menggunakan modifikasi sebagian taksonomi yang terdapat pada model keberhasilan sistem informasi. Sistem yang akan diajukan menggunakan metode penyebaran kuesioner secara online, kuesioner akan diisi melalui web sehingga tidak perlu untuk menyebar dan mengumpulkan kembali kuesioner yang telah diisi oleh stakeholder.

Penelitian yang dilakukan ini menggunakan model penelitian waterfall dimana tahapan penelitian dimulai dengan pengumpulan data yang diperoleh dari alumni yang telah bekerja, kemudian analisis sistem, desain sistem, pembuatan program mengunaakan $P H P$ dengan database MySQL, uji coba akan dilakukan menggunakan dua (2) hal, yaitu pengujian system dan pengujian oleh responden, tahap terakhir yaitu analisis hasil sistem [10].

\section{METODE PENELITIAN}

a. Flowmap Sistem

Tahap pertama yang dilakukan dalam penelitian ini adalah untuk merancang seluruh alur dari sistem survei kepuasan stakeholder yang dibuat. Flowmap sistem yang dirancang terlihat pada Gambar 1. Gambar 1 menjelaskan alur sistem yang dibuat, tahap pertama pada sistem survei kepuasan stakeholder yaitu Admin akan menambahkan data stakeholder yang telah diisikan di tracer study oleh alumni, kemudian Admin mengirimkan id dan password kepada stakeholder melalui email, setelah itu stakeholder login ke sistem survei dilanjutkan dengan mengisi kuisoner sesuai dengan nama alumni yang akan muncul pada sistem, kemudian Admin dapat melakukan cetak laporan hasil survei berupa grafik ataupun data dalam tabel untuk kemudian dilakukan evaluasi hasil dari kuisioner yang telah diisikan. Laporan hasil survei akan digunakan oleh LPMA 
melalui Divisi Pemberdayaan Alumni, untuk lebih meningkatkan kualitas alumni untuk lulusan yang akan datang.

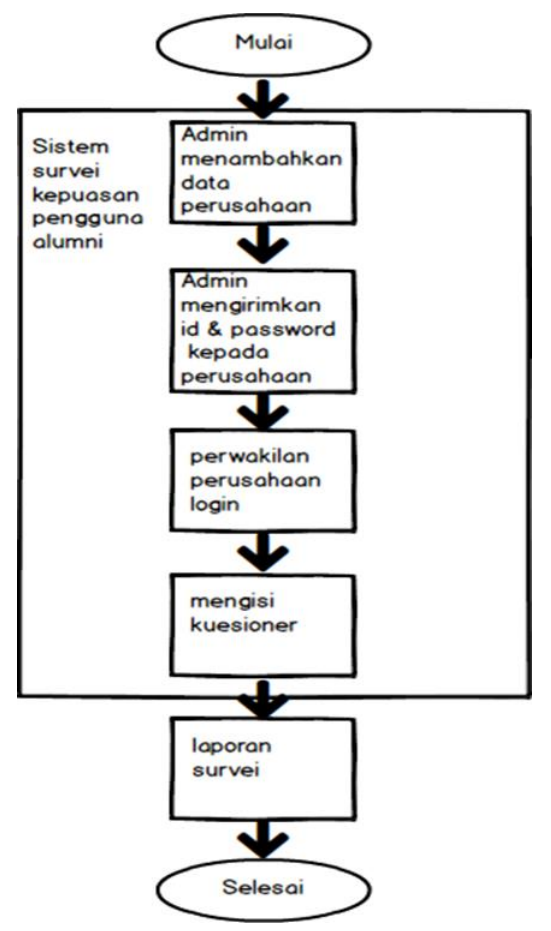

Gambar 1 Flowmap Sistem

Berdasarkan analisis sistem maka akan dibuat perancangan sistem secara keseluruhan dengan menggunakan Unified Modelling Language (UML) sebagai gambaran alur sistem, Entity Relasionship Diagram (ERD) sebagai perancangan database, Bahasa pemrograman PHP untuk implementasi sistem, dan database menggunakan MySQL.

b. Perancangan Proses Sistem

Tujuan utama dari perancangan sistem adalah memberikan gambaran perancangan sistem yang akan dibangun atau dikembangkan, serta untuk memahami alur informasi dan proses dalam sistem melalui penggambaran Use Case Diagram, Class Diagram, Activity Diagram, dan Sequence Diagram.

\section{1) Rancangan Usecase Diagram}

Usecase diagram dapat dilihat pada gambar 2 memperlihatkan dua aktor, yaitu admin dan stakeholder. Admin adalah pihak dari Tata Usaha Fakultas Teknik dan stakeholder adalah pengisi kuesioner (stakeholder). Disini admin ataupun stakeholder tidak dapat melakukan aktifitas di sistem jika tidak melakukan login terlebih dahulu. Setiap aktor meliliki Batasan akses, yaitu Admin berwenang menambah data stakeholder, menghapus data stakeholder, melihat data stakeholder, mengubah data stakeholder, melihat hasil kuesioner, menambah data alumni, melihat data alumni, menghapus data alumni, menghapus data alumni, mengubah data alumni. Sedangkan aktor stakeholder bisa mengubah data stakeholder dan mengisi kuesioner. 


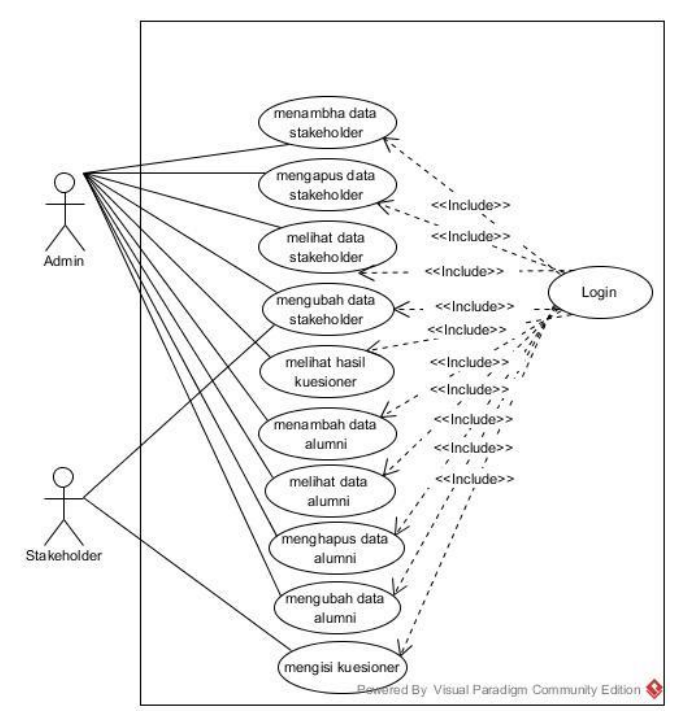

Gambar 2 Usecase diagram

2) Rancangan Diagram Activity

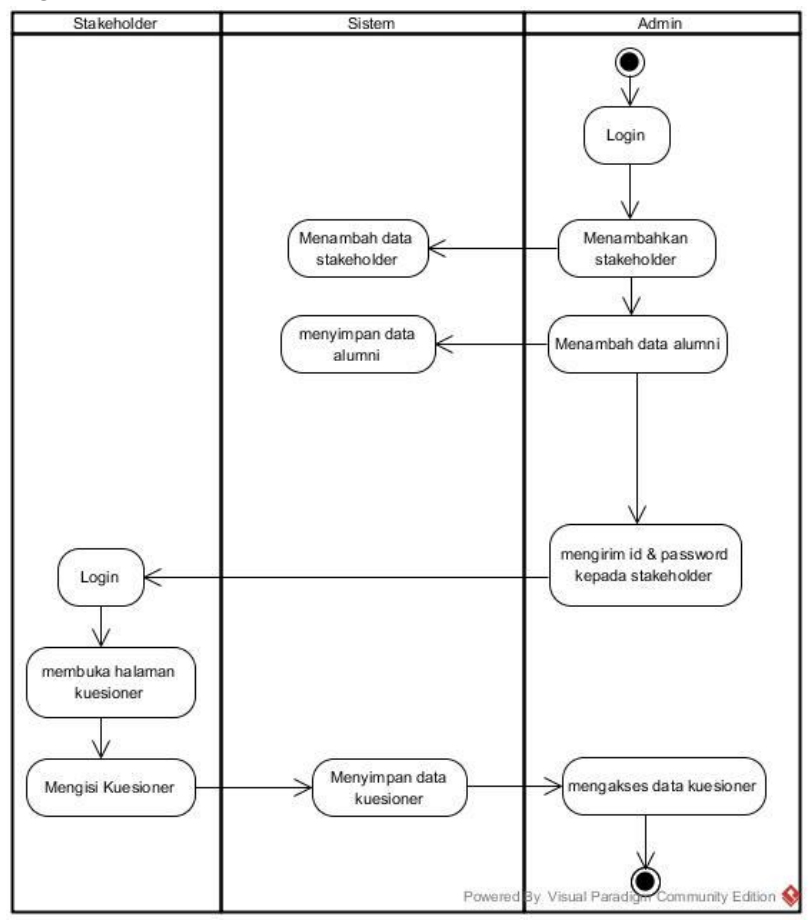

Gambar 3 Diagram Activity

Gambar 3 menjelaskan tentang Activity diagram yang menggambarkan aktifitas yang terjadi. Admin setelah melakukan login dapat menambahkan stakeholder di sistem akan menambahkan data stakeholder, selanjutnya admin menambahkan data alumni dan sistem akan menyimpan data alumni, admin akan mengirimkan id dan password stakeholder kepada stakeholder, stakeholder akan login menggunakan id dan password yang dikirimkan admin, stakeholder membuka halaman Alumni di sistem akan menampilkan halaman alumni setelah itu stakeholder akan mengisi kuesioner, disistem akan menyimpan jawaban dari stakeholder dan admin mengakses data hasil pengisian kuesioner. 
3) Rancangan Sequence Diagram

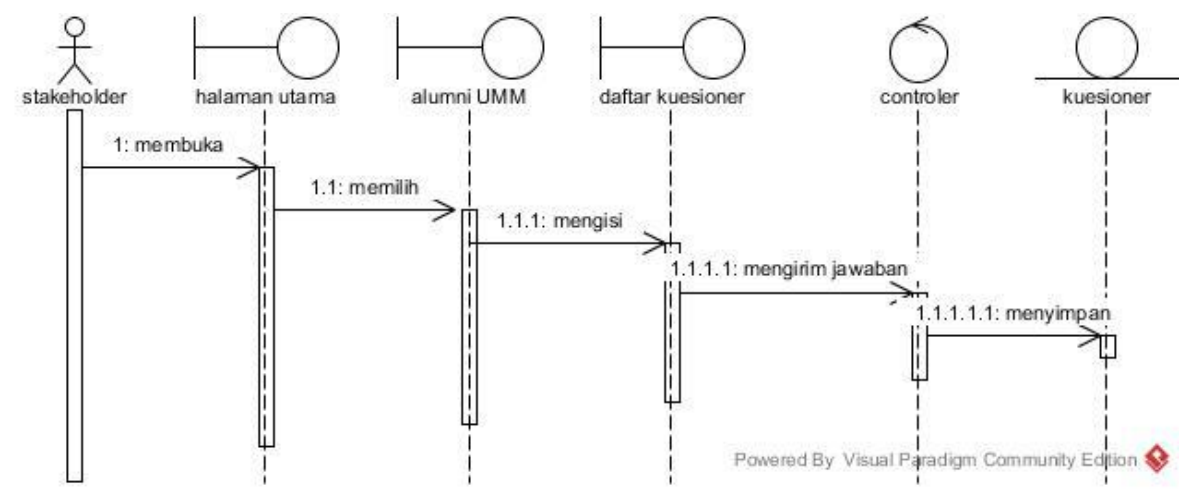

Gambar 4 Sequence diagram isi kuisoner

Sequence diagram mengisi kuesioner menggambarkan cara stakeholder mengisi kuesioner. Stakeholder masuk ke halaman utama dan memilih kuesioner lalu melihat daftar kuesioner dan mengisi kuesioner setelah itu hasil kuesioner akan di simpan di database kuesioner.

c. Perancangan basis data

Tahapan selanjutnya untuk merancang basis data, dalam penelitian ini akan digunakan ERD dalam perancangan basis data.

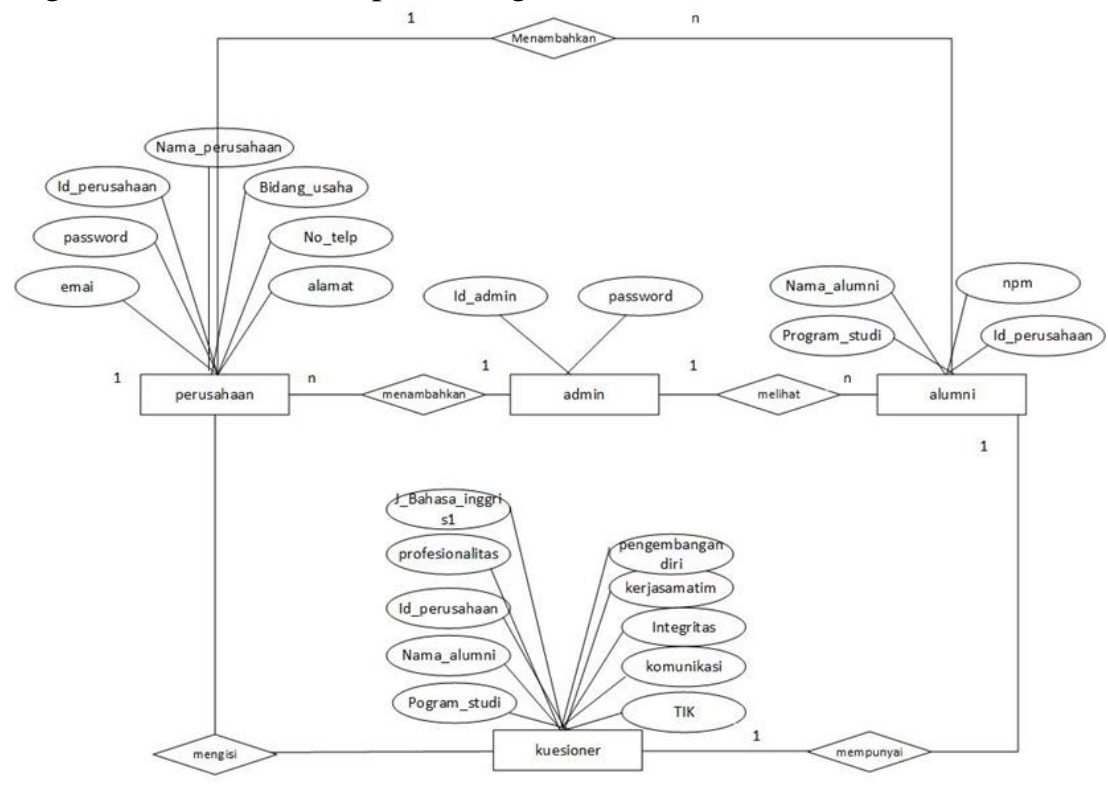

Gambar 5 Entity Relationship Diagram (ERD)

Entity relationship diagram menggambarkan hubungan yang terjadi antara empat entitas, yaitu entitas admin, entitas stakeholder, entitas alumni dan entitas kuesioner. Adapun hubungan antara entitas tersebut adalah admin mempunyai relasi 1:N alumni, yaitu menjelaskan bahwa Admin dapat melihat banyak Alumni, relasi antara admin dan stakeholder 1:N yaitu Admin dapat menambahkan banyak stakeholder, stakeholder mempunyai relasi 1:N kusioner yaitu stakeholder dapat mengisi banyak kusisioner, dan alumni 1:1 kuisioner yaitu dengan 1 alumni hanya dapat mengisikan 1 kuisioner. 


\section{HASIL DAN PEMBAHASAN}

a. Perancangan Interface

1) Interface mengisi kuisioner

Perancangan interface ini dibuat untuk memudahkan pihak stakeholder dalam mengisikan hasil dari penilaian ke alumni yang terkait.

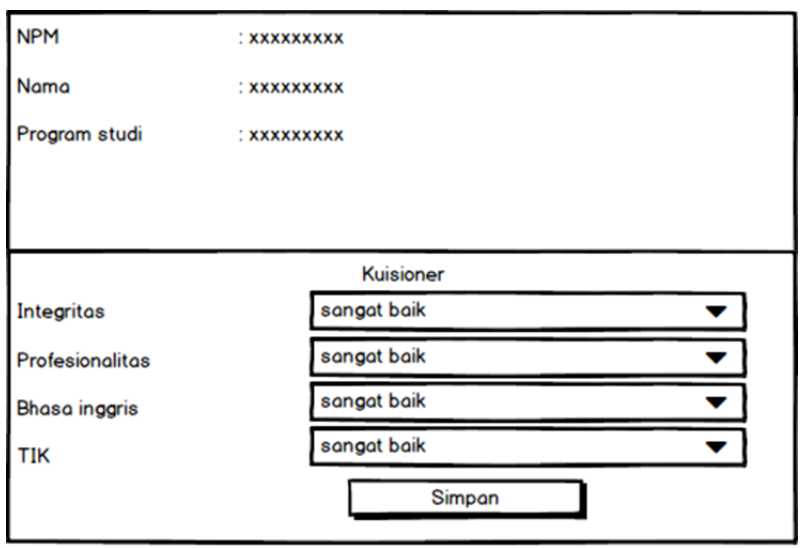

Gambar 6 interface pengisian kuisoner

Halaman ini menampilkan halaman data alumni yang bekerjasama dengan pihak stakeholder tersebut serta terdapat aspek-aspek pertanyaan kuesioner. Jika stakeholder sudah selesai maka data penilaian akan di masukan kedalam database alumni.

2) Interface halaman grafik

Halaman grafik digunakan untuk menampilkan seluruh hasil dari penilaian oleh pihak stakeholder.

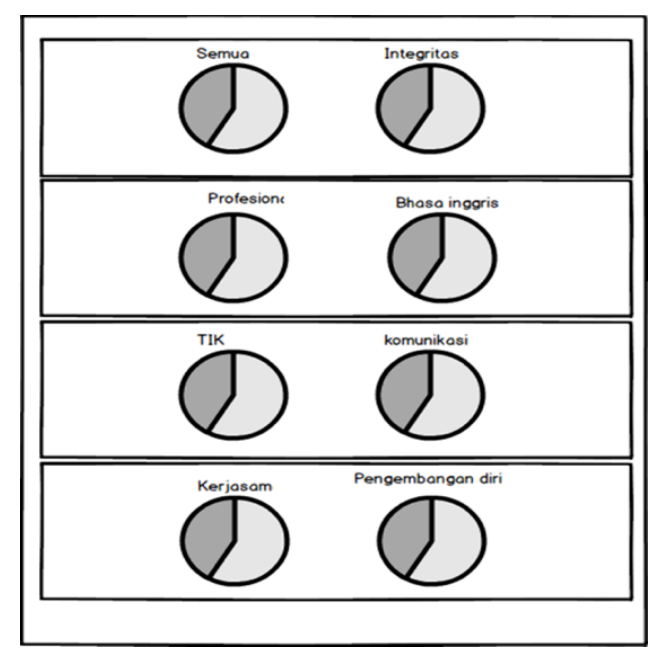

Gambar 7 Rancangan interface grafik

Halaman ini menampilkan hasil penilaian yang sudah di lakukan oleh stakeholder. Hasil penilaian berupa grafik untuk memudahkan membaca data. Hasil penilaian dapat di print agar bisa digunakan sebagai bahan laporan. 
b. Hasil

Penelitian ini bertujuan untuk menghasilkan sistem Survei Kepuasan Stakeholder Berbasis Web (Studi Kasus Alumni Fakultas Teknik Universitas Muhammadiyah Magelang). Setelah sistem ini dibuat langkah selanjutnya yang dilakukan yaitu melakukan uji coba dengan cara digunakan langsung oleh user, untuk mengetahui apakah sistem dibuat dapat berjalan sesuai fungsinya. Dengan adanya sistem Informasi Survei Kepuasan Stakeholder ini diharapkan dapat membantu pihak fakultas untuk memperoleh hasil dari penilaian alumni didunia kerja, memudahkan pada saat pengumpulan data penilaian tanpa harus terjun lapangan secara langsung. Pada penelitian ini sistem informasi yang digunakan adalah berbasis web.

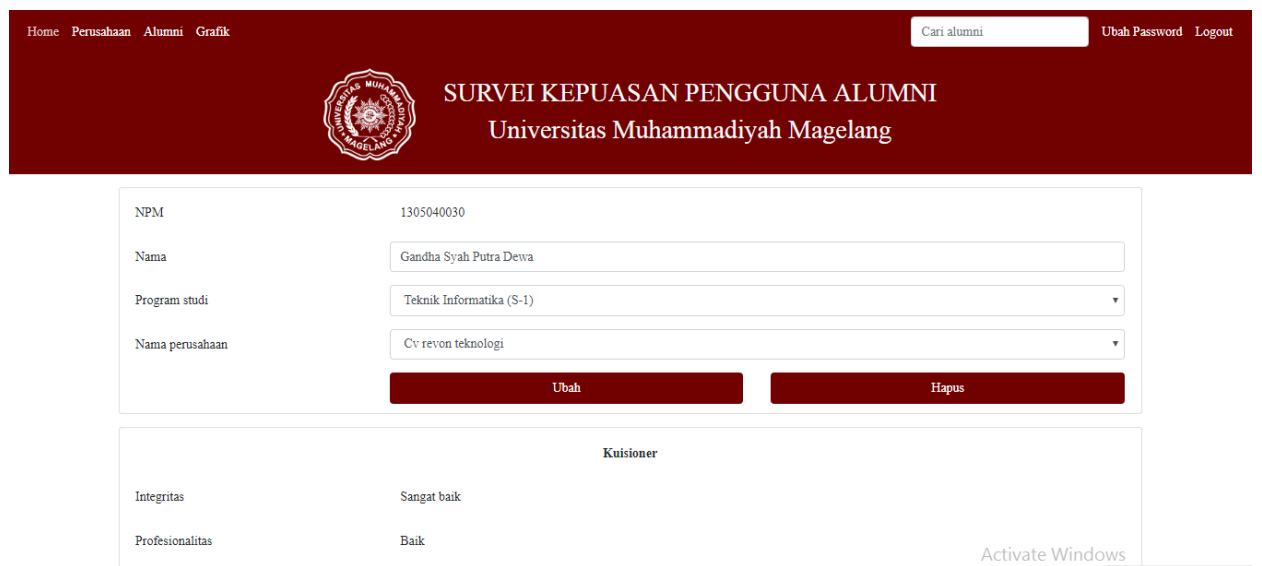

Gambar 8 Halaman Hasil Penilaian Alumni

Pada gambar diatas menunjukan hasil penilaian alumni dari pihak stakeholder terkait - Alumni dinilai satu per satu sesuai tempat kerja dan hasil penilaian akan masuk ke data alumni satu per satu. Admin dapat mengetahui hasil penilaian tersebut tanpa bisa mengubah hasil penilaian dari stakeholder. Dihalaman ini terdapat Npm, Nama, Program studi serta Nama stakeholder tempat Alumni bekerja.

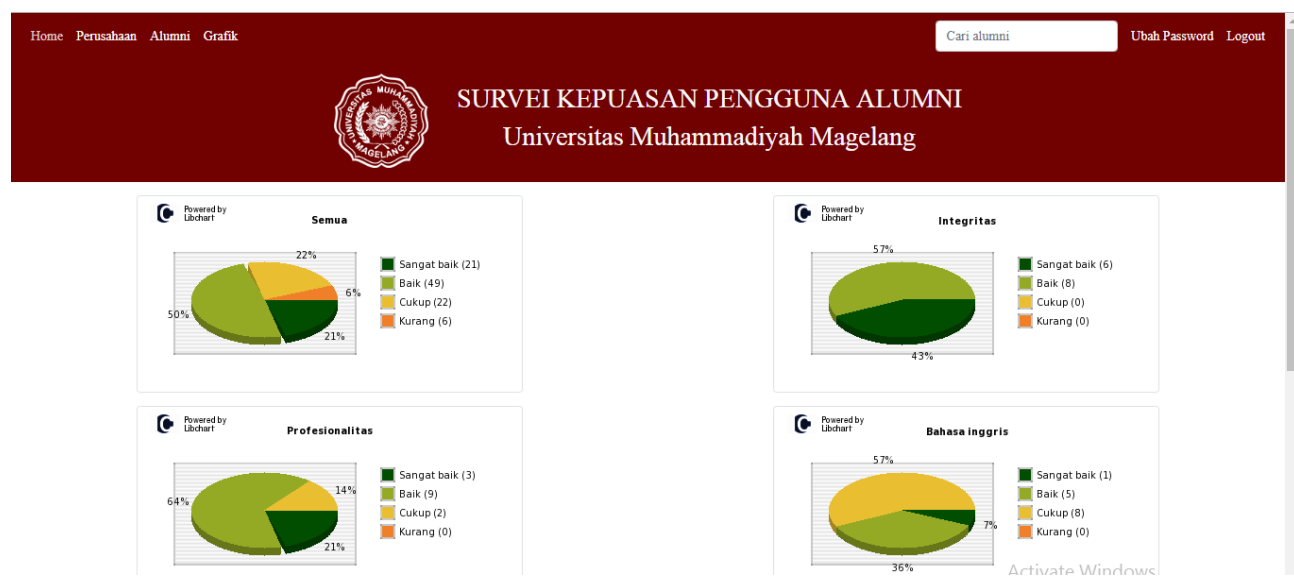

Gambar 9 Grafik Hasil Penilaian Alumni

Gambar diatas menunjukan hasil penilaian dalam bentuk grafik. Admin dapat mengetahui secara rinci tentang penilaian alumni. Halaman ini menampilkan hasil penilaian dalam bentuk grafik sesuai kriteria pertanyaan dalam kuisioner. Hasil ini adalah mutlak tidak dapat diubah Admin. Hasil dapat dicetak dengan menekan tombol print. 
c. Pembahasan

Sistem Survei Kepuasan Stakeholder ini digunakan oleh Fakultas dan stakeholder dalam melakukan kegiatan penilaian. Sistem ini dibangun sudah sesuai dengan perancangan sistem yang dibuat, antarmuka pada sistem informasi sudah sesuai dengan rancangan awal, dan basis data yang digunakan sudah sesuai dengan kebutuhan pada sistem. Sistem memiliki dapat bermanfaat bagi fakultas karena fakultas dapat mengarsipkan file-file data alumni, data stakeholder dan hasil penilaian dapat tersimpan dalam sistem. Pihak fakultas dapat menyelenggarakan kegiatan ini tanpa bertemu secara langsung dengan pihak stakeholder.

Kelebihan sistem survei stakeholder ini adalah fakultas dapat melaksanakan penilaian alumni tanpa harus menyebar kuisioner ke stakeholder terkait, fakultas tidak perlu melakukan perhitungan secara manual, tidak harus turun langsung ke pihak stakeholder, pengumpulan data lebih efisien dan mudah untuk dicari, sistem menghasilkan perhitungan yang akurat serta hasil yang didapat dituangkan kedalam bentuk grafik. Kekurangan Sistem belum mempunyai suatu menu yang berisi tentang informasi alumni masih bekerja di stakeholder terkait atau sudah berhenti.

Sistem survei kepuasan stakeholder meliputi 2 pengujian sistem yaitu:

1. Pengujian balckbox

Pengujian blackbox meliputi 2 user yaitu admin dan stakeholder.

\section{a. Admin}

Pengujian halaman login yaitu melakukan proses verifikasi data user dengan skenario menginputkan id dan password untuk hasil yang diharapkan yaitu berhasil login, jika berhasil maka mendaptkan hasil valid. Pengujian menu stakeholder dari pihak admin, guna menguji apakah sistem dapat menampilkan data stakeholder, skenario yang dilakukan adalah mengklik tombol stakeholder, jika berhasil maka halaman akan menuju ke halaman stakeholder dimana terdapat isi semua data stakeholder. Pengujian tombol tambah stakeholder, ubah, hapus, lihat selengkapnya pada menu alumni dengan hasil valid. Pengujian menu alumni dari pihak admin, guna menguji apakah sistem dapat menampilkan data alumni, skenario yang dilakukan adalah mengklik tombol alumni, jika berhasil maka halaman akan menuju ke halaman alumni dimana terdapat isi semua data stakeholder. Pengujian tombol tambah alumni, ubah, hapus, lihat selengkapnya pada menu alumni dengan hasil valid. Pengujian menu grafik dengan skenari yang dilakukan adalah klik tombol grafik dengan hasil yang diharapkan muncul halaman grafik dari hasil penilaian kepuasaan dari pihak stakeholder. Pengujian tombol print dengan skenario pengujian klik tombol print maka menghasilkan data berupa print pdf dengan isi hasil dari penilaian kepuasan. Pengujian menu cari dengan skenario menuliskan npm ataupun nama stakeholder maka akan muncul hasil dari pencarian berupa data yang dicari. Pengujian menu ubah password menghasilkan form ubah password yang bisa diubah oleh admin.

b. Stakeholder

Pengujian halaman login yaitu dengan menginputkan id dan password dengan hasil yang diharapkan login berhasil dengan masuk ke halaman utama sistem. Pengujian menu alumni UMM dengan mengklik menu alumni UMM dengan hasil yang diharapkan muncul halaman berupa data semua alumni. Pengujian menu ubah password dengan mengklik menu ubah password dengan hasil yang diharapkan muncul halaman ubah password dan password berhasil diubah.

\section{Acceptance testing}

Pengujian penerimaan sistem dilakukan oleh pihak staff tenaga kependidikan yaitu Shela Rachmawati dan stakeholder terkait sebagai user stakeholder. Bukti terlampir uji coba yang dilakukan dapat dilihat pada bagian lampiran. Berikut adalah hasil uji coba yang telah dilakukan. Hasil pengujian yang dilakukan oleh staff Tata Usaha menghasilkan nilai angka 
86\% dapat disimpulkan bahwa acceptance Tata Usaha terhadap sistem masuk kategori puas. Hasil pengujian yang dilakukan oleh sepuluh (10) stakeholder mendapatkan hasil perhitungan angka 66\% dapat disimpulkan bahwa acceptance stakeholder terhadap sistem masuk kategori cukup. Hasil akhir pengujian yang dapat disimpulkan adalah rata-rata persentase dari hasil lembar kuesioner 2 user sebesar $76 \%$ yang artinya sistem cukup sesuai dengan kebutuhan pengguna.

a. Kesimpulan

\section{KESIMPULAN DAN SARAN}

Dari pembahasan yang sudah diuraikan maka penulis mencoba membuat kesimpulan sebagai berikut:

1. Dengan sistem informasi survei stakeholder, fakultas dapat memonitoring kualitas alumni didunia kerja berdasarkan hasil penilaian dari stakeholder tempat alumni bekerja.

2. Penambahan data alumni dan stakeholder dapat dilakukan melalui sistem serta stakeholder dapat melakukan penilaian alumni melalui sistem tersebut.

3. Dari hasil uji coba yang dilakukan kepada pihak tata usaha serta stakeholder maka didapat hasil angka $76 \%$ yang artinya responden cukup puas dengan sistem.

b. Saran

Pengkajian dari sistem informasi survei penguna alumni ini mungkin masih dapat dikembangkan lagi dengan menambahkan menu untuk mengetahui apakah alumni masih bekerja di stakeholder atau sudah berhenti. Kemudian juga tampilan atau desain antarmuka dari tampilan ini mungkin dapat dibuat lebih menarik lagi.

\section{DAFTAR PUSTAKA}

[1] H. Hermanto Totok, Furqan Moh., "SISTEM INFORMASI ADMINISTRASI TRACER STUDY DAN KEPUASAN STAKEHOLDERS ALUMNI STT NURUL JADID BERBASIS WEB," J. Tek. Inform., vol. 07, 2017.

[2] W. Sholihah and H. D. Azra, "APLIKASI SURVEI KEPUASAN MAHASISWA BERBASIS WEB DI,” no. 2015, pp. 24-34, 2016.

[3] M. Indriani, M. Sholihin, and N. F. Apriliani, "Aplikasi Pengisian Data Alumni Prodi Teknik Universitas Islam Lamongan Berbasis Android," pp. 1-6.

[4] D. Qassim Jawad and D. Reeves, "SWP 12/97 SUCCESSFUL ACQUISITION OF IT SYSTEMS."

[5] M. Bergersen, "User satisfaction and influencing issues B ${ }^{\circ}$ What is meant by " end-user '? Evolvement of End-User Computing," pp. 5-26, 2005.

[6] M. Zrivan, N. Pliskin, R. Levin, and M. Zviran, "Measuring User Satisfaction and Perceived Usefulness in the Erp Context," J. Comput. Inf. Syst., vol. 45, no. 3, pp. 43-52, 2005.

[7] E. R. Arumi and U. Yudatama, "Pemanfaatan Curiculum Vitae dan Sasaran Kinerja Pegawai untuk Penilaian Kinerja Dosen Menggunakan AHP," J. RESTI (Rekayasa Sist. dan Teknol. Informasi), vol. 1, no. 3, pp. 170-176, Nov. 2017.

[8] M. A. Bora, “Analisa Kepuasan Penggunaan E-Learning Cloud Sekolah Tinggi Teknik ( STT ) Ibnu Sina Batam," J. Kreat. Ind., vol. 1, no. 1, pp. 55-62, 2017.

[9] A. Ardianto, S. Fauziati, and E. Nugroho, "Faktor-Faktor Yang Mempengaruhi Kepuasan Pengguna Akhir Sistem Informasi Sumber Daya Manusia (Studi Kasus Di 
BPK RI)," Semin. Nas. Teknol. Inf. dan Multimed., pp. 29-34, 2014.

[10] J. Lemantara, N. A. Setiawan, and M. N. Aji, "Rancang Bangun Sistem Pendukung Keputusan Pemilihan Mahasiswa Berprestasi Menggunakan Metode AHP dan Promethee," Jnteti, vol. 2, no. 4, pp. 20-28, 2013. 